Article

\title{
Performance of Date Palm Ash as a Cementitious Material by Evaluating Strength, Durability, and Characterization
}

\author{
Muhammad Nasir ${ }^{(D)}$ and Walid Al-Kutti * \\ Department of Civil and Construction Engineering, College of Engineering, Imam Abdulrahman Bin Faisal \\ University, Dammam 31451, Saudi Arabia; mnmuhammad@iau.edu.sa \\ * Correspondence: wasalem@iau.edu.sa
}

Received: 28 November 2018; Accepted: 20 December 2018; Published: 28 December 2018

\begin{abstract}
Cement manufacturing is indeed a major contributor to global warming that involves energy-intensive production processes along with emitting huge greenhouse gasses into the atmosphere. To adopt sustainable construction practices, agro-industrial waste materials as supplementary cementitious materials (SCMs) have been used by numerous researchers to partially replace conventional ordinary Portland cement (OPC) with SCMs by evaluating its optimum replacement dosage. This study aims to: (1) highlight the background of the date palm tree and the application of date palm waste as a construction material; (2) optimizing the dosage of date palm ash (DPA) as a cementitious material, at the replacement level of $10 \%, 20 \%$, and $30 \%$; and (3) understand the reaction kinetics by way of characterization techniques. DPA-based binary mixes were compared with each other and with the control (100\% OPC mix) through fresh, mechanical, durability, and microstructural properties. The mechanism of reaction at early- and long-term period of curing was studied by characterization tests on paste, including nitrogen adsorption test (BET), X-ray diffraction (XRD), thermogravimetric analysis (TGA), Fourier transform infrared spectroscopy (FT-IR). The outcome revealed $10 \%$ DPA as a strong and durable substitute to OPC, by formation of more Calcium Silicate Hydrate (C-S-H) and Calcium Aluminosilicate Hydrate (C-A-S-H) gel, whereas up to $30 \%$ DPA replacement can further maximize clinker replacement with reasonable performance, together with enhanced sustainability and reduced construction cost.
\end{abstract}

Keywords: date palm ash (DPA); supplementary cementitious materials (SCMs); optimum dosage; strength; sorptivity; microstructure; hydration products

\section{Introduction}

The demand of cement is continuously increasing worldwide due to the construction boom. Production of cement is considered as environmentally unfriendly because of its energy-intensive process and drawback of releasing high $\mathrm{CO}_{2}$ into the atmosphere. According to the Cement Sustainability Initiative (CSI), global cement production has reached from $500 \mathrm{Mt}$ in 1990 to $900 \mathrm{Mt}$ in 2015 [1]. It is reported that 2\% world energy and 5\% world industrial energy is consumed by the cement sector, which is responsible for emitting $5 \%$ of world $\mathrm{CO}_{2}$ emissions [2]. If $\mathrm{CO}_{2}$ emissions are not controlled below $50 \mathrm{Gt}$, it is likely to endanger global warming risk by exceeding the $2{ }^{\circ} \mathrm{C}$ Earth temperature limit [3].

$\mathrm{CO}_{2}$ emissions can be minimized by adopting the following approaches: (1) using supplementary cementitious materials (SCMs) as partial replacement of traditional cement from agro-industrial and natural waste material, including palm oil fuel ash, rice husk ash, fly ash, ground steel slag, natural pozzolan, and metakaolin; (2) developing geopolymer concrete (OPC-free); (3) carbon capturing; and 
(4) changing fuel sources and modifying clinker production process. According to US Portland Cement Association (US-PCA) [4], alternative cementitious material as partial replacement is the most effective way of lowering $\mathrm{CO}_{2}$ emissions, which can readily be applied at cement and ready-mix plants at a lower cost.

The need for recycling agricultural waste is also important because these wastes are often burnt in an open-field to easily and quickly maximizing crop rotation. Waste burning emits harmful elements and gases like soot and carbon monoxide that diffuses in the air and leads to several atmospheric contamination and human diseases [5].

Aforementioned problems prompted development of successful construction products earlier based on tree wastes, notably from bamboo, coconut, corn, date palm, elephant grass, olive, oil palm, rice husk, sugarcane bagasse, and wheat straw [6]. Among these agricultural wastes, date palm is often overlooked in the literature which has potential to be incorporated as SCM.

Date palm tree is registered as one of the oldest and top number of trees worldwide. It is reported that about 105 million date palm trees are currently existing [7]. Productivity rate of these trees are continuously increasing and recorded to increase from 6.54 million tons to 7.42 million tons during the period of 2004 to 2009, respectively [7]. According to a report of United Nation's (UN) Food Authorization Organization (FAO), the global highest productivity of dates was recorded around 7.2 million tons in 2010. A mature age date palm tree has around 125 greenish palms, from which every year up to 25 new leaves are formed and up to 25 leaves are required to pluck during the seasonal fruit collection [8,9]. Date palm is the most popular crop cultivated in many parts of the world, especially in the Arab world. Saudi Arabia is known as the mother land for, and origin of, date palm trees, where these trees were originated 10,000 years ago [10]. It is estimated that more than 300 types of date fruits are available in the Arabian Peninsula.

In construction engineering application, the incorporation of date palm waste is uncommon as a cementitious material. For instance, as a cementitious material, Khellou et al. [11] started the incorporation of $4 \%-12 \%$ of date palm ash with crusting tuff blends and investigated the mechanical properties of the Algerian pavement construction. The authors found potential possibility in extension of their research from their results that $8 \%$ ash dosage yields an optimum mix, which can significantly improve the compression strength and bearing index. Likewise, Al-Kutti et al. [12,13] replaced up to $30 \%$ traditional cement with date palm ash (DPA) in concrete and mortar mixes. They observed that $10 \%$ DPA content dramatically improves the mechanical and durability characteristics. Recently, the suitability of date palm seed ash (DPSA) by partial replacement of Type I cement, at an interval of $2 \%$, from $0 \%-10 \%$, was investigated by Gunarani and Chakkravarthy [14]. They investigated strength, rate of water absorption, and durability of mortar in an alkaline environment. Their results revealed that $4 \%$ DPSA was the optimum replacement dosage to Type I cement, whereas $2 \%$ and $8 \%$ replacement dosages may also be effectively utilized in structure exposure to acid attack and higher bond strength requirement, respectively.

The review of literature indicates that knowledge gaps exist to explore date palm ash as a cementitious material, evaluate its long-term strength and durability performance, as well as to understand its microstructural characteristics. Therefore, the primary objective of this research is to develop local Arabian Gulf date palm ash-based construction product by replacing traditional cement. Moreover, it is aimed to establish and understand fresh, mechanical, durability, and microstructural characteristics of the binder. The experimental investigation includes determination of the flow, compressive strength, and sorptivity on mortar or concrete samples prepared with different dosages of date palm ash, up to 360 days. Analytical tests included Brunauer, Emmett and Teller (BET), thermogravimetric analysis (TGA), X-ray diffraction (XRD) and Fourier transform infrared (FTIR) on paste specimens. 


\section{Materials and Methods}

\subsection{Materials}

\subsubsection{Ordinary Portland Cement and Date Palm Ash}

Type I-ordinary Portland cement (OPC) was utilized in all mixtures. The specific gravity and maximum particle size of OPC was 3.44 and $0.075 \mathrm{~mm}$, respectively. Date palm ash (DPA) was procured from a farm located in Eastern Saudi Arabia, where a farmer collects the palm waste from nearby farms and recycles them to form firewood and charcoal, while using same waste as a fuel material. The by-product of burning waste is called date palm ash. About 3 tons of firewood and 1.5 tons of coal is daily produced, which generates $10 \%-20 \%$ of the DPA at a plant. Figure 1 shows the stages of the production of valuable products and waste generation at the recycling plant as follows: (a) dried date palm tree fronds are trimmed, (b) raw date palm tree waste is dried in open air and sun for one day and transported to the plant, (c) raw material is grinded, passing through a $8 \mathrm{~mm}$ diameter sieve, using a hammer mill, (d) crushed raw material is passed to the compression machine and shaped, (e) fire wood is produced, (f) wood is placed in an environmental friendly oven and burnt up to $700{ }^{\circ} \mathrm{C}$ for $6 \mathrm{~h}$ using raw material as fuel, (g) wood is transformed into charcoal, and (h) fuel material is converted into ash (DPA). The specific gravity and maximum particle size of DPA was 2.43 and $0.150 \mathrm{~mm}$, respectively.
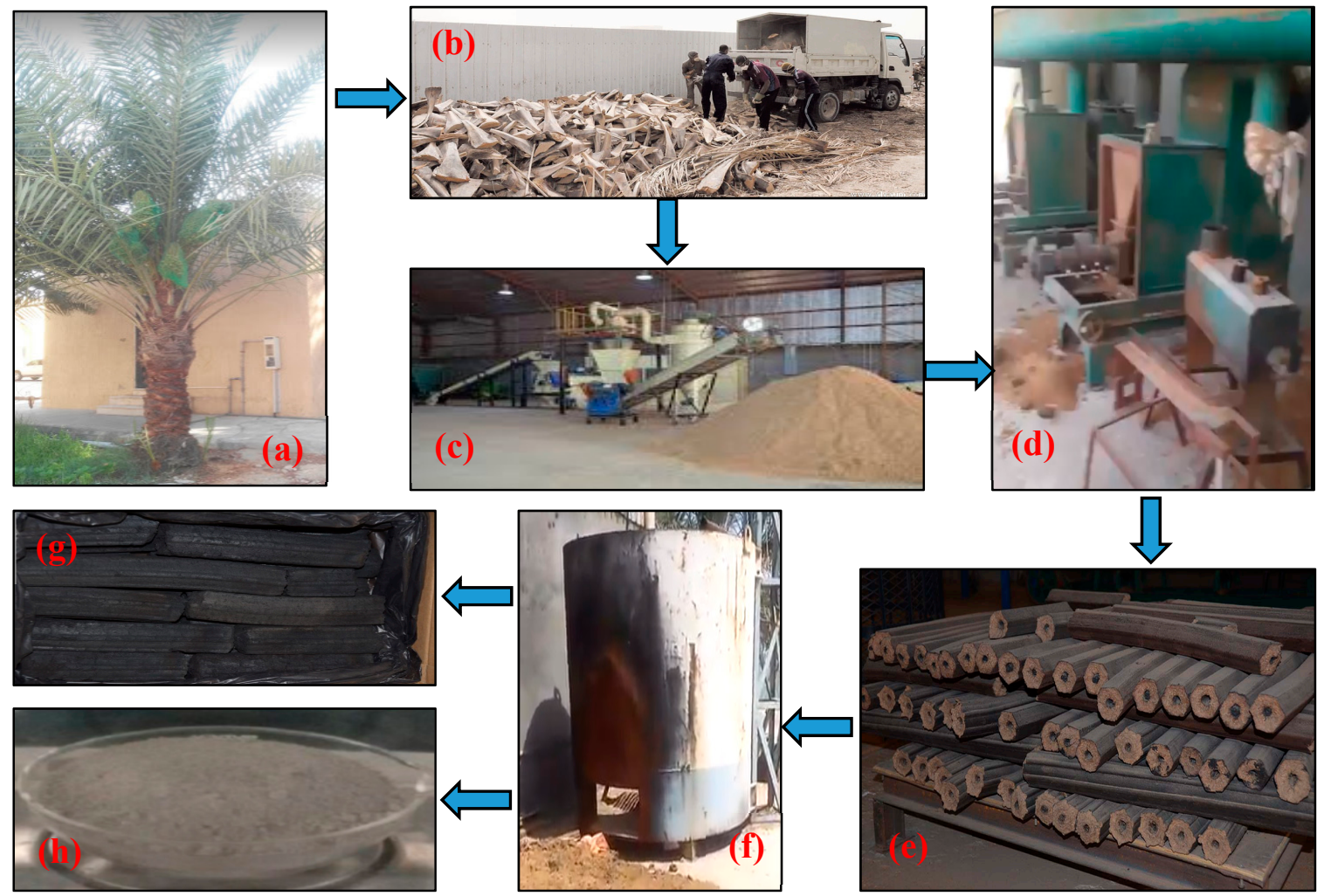

Figure 1. Stages of recycling: (a) typical date palm tree, (b) raw waste, (c) grinding, (d) compressing and molding machine, (e) firewood formation, (f) oven, (g) charcoal formation, and (h) DPA generation.

\subsubsection{Fine Aggregate and Coarse Aggregate}

Dune sand was incorporated as fine aggregate (FA) having bulk specific gravity, absorption, and maximum particle size of $2.82,0.7 \%$, and $0.425 \mathrm{~mm}$, respectively. Crushed limestone was utilized as coarse aggregate (CA) having bulk specific gravity, absorption, and maximum particle size of 2.6, 1.1\%, and $19 \mathrm{~mm}$, respectively. The grading requirement of CA was fulfilled as per ASTM C 33. 


\subsubsection{Preparation of Specimens}

Total of 4 mixtures were cast, each of paste, mortar, and concrete, by replacing OPC with DPA $(0 \%-30 \%)$ with an interval of $10 \%$. Water to cementitious material ratio and FA to CA ratio was kept invariant as 0.4 and 0.7 , respectively. Cubic paste specimens $25 \mathrm{~mm}$ in size were prepared for analytical tests, mortar was prepared for the flow table test, and $50 \mathrm{~mm}$ cubic mortar specimens were prepared for compressive strength test, while $100 \mathrm{~mm}$ diameter $\times 200 \mathrm{~mm}$ high cylindrical concrete specimens were prepared for the sorptivity test. The constituent of mortar (cementitious material, FA and water) and paste (mortar excluded FA) was proportioned as per the guidelines of ASTM C 109. The typical mixture proportion of concrete specimen consisted: cementitious material $=350 \mathrm{~kg} / \mathrm{m}^{3}$, $\mathrm{FA}=733 \mathrm{~kg} / \mathrm{m}^{3}, \mathrm{CA}=1099 \mathrm{~kg} / \mathrm{m}^{3}$ and water $=167 \mathrm{~kg} / \mathrm{m}^{3}$. First, dry materials were introduced in the mixer followed by mixing water and/or superplasticizer. The ingredients were mixed for a total duration of 6 to $8 \mathrm{~min}$. The dough was placed in oiled molds in two layers, consolidated for $15 \mathrm{~s}$ on vibration table, and the top surface finished by trowel. The molds were plastic-wrapped and placed at room temperature at $25 \pm 3{ }^{\circ} \mathrm{C}$ for $24 \mathrm{~h}$. Thereafter, molds were opened and specimens were placed under water until the test ages.

\subsection{Test Methods}

\subsubsection{Chemical Composition Analysis}

Table 1 shows the chemical composition of OPC and DPA evaluated through X-ray fluorescence (XRF) technique using the PANalytic apparatus. OPC has major oxides of $\mathrm{Si}, \mathrm{Ca}$, and $\mathrm{Al}$ and minor traces of $\mathrm{Fe}$ and $\mathrm{Mg}$, whereas DPA constituted major oxides of $\mathrm{Si}, \mathrm{Ca}, \mathrm{Mg}$, and $\mathrm{K}$ and minor traces of $\mathrm{Fe}$ and $\mathrm{Al}$. The sum of the oxides of $\mathrm{Si}, \mathrm{Ca}, \mathrm{Mg}$, and $\mathrm{K}$ in DPA was above $80 \%$. By partial replacement of OPC by DPA in binary binders, $\mathrm{Si}, \mathrm{Mg}$, and $\mathrm{K}$ content increased while Ca content decreased.

Table 1. Chemical composition of DPA and OPC.

\begin{tabular}{|c|c|c|c|c|c|c|c|c|c|c|c|c|c|c|}
\hline \multirow{2}{*}{ Material } & \multicolumn{14}{|c|}{ Oxides Wt. (\%) } \\
\hline & $\mathrm{SiO}_{2}$ & $\mathrm{CaO}$ & $\mathrm{MgO}$ & $\mathrm{Fe}_{2} \mathrm{O}_{3}$ & $\mathrm{~K}_{2} \mathrm{O}$ & $\mathrm{Al}_{2} \mathrm{O}_{3}$ & $\mathrm{Cl}$ & $\mathrm{SO}_{3}$ & C & $\mathrm{Na}_{2} \mathrm{O}$ & $\mathbf{P}_{2} \mathrm{O}_{5}$ & SrO & LOI & Sum \\
\hline DPA & 42.2 & 19.2 & 14.1 & 3.2 & 5.7 & 1.1 & 7.0 & 3.6 & 0.4 & 0.9 & 1.0 & 0.3 & 1.1 & 99.8 \\
\hline OPC & 23 & 64.4 & 1.5 & 3.8 & 0.3 & 5.6 & - & - & - & 0.2 & - & - & 0.7 & 99.6 \\
\hline
\end{tabular}

\subsubsection{Surface Area and Pore Volume}

Surface area and pore volume was measured on paste binders using B.E.T-Nitrogen adsorption test by means of Quantachrome instrument.

\subsubsection{Flow}

The flow of fresh mortar was measured by flow table as per ASTM C 1437, right after mixing operation. The flow was measured in four directions and average values were reported.

\subsubsection{Compressive Strength}

Compressive strength was evaluated on $50 \mathrm{~mm}$ cubic mortar specimens for the water cured ages of up to 360 days, using compression testing machine applying a uniform load. This test was conducted as per ASTM C 109. The average of three test specimens (whose standard deviation was within the allowable limit) were reported as compressive strength.

\subsubsection{Rate of Water Absorption}

Rate of water absorption or sorptivity test was conducted on concrete specimens at 28 and 360 days, as per ASTM C1585. Cylindrical specimens $(100 \times 200 \mathrm{~mm})$ were first sliced using a saw cutter in order to obtain $50 \mathrm{~mm}$ thick and $100 \mathrm{~mm}$ diameter disks. The sides and top surface of the 
disks were wrapped by strong sticky tape and plastic sheet, respectively. Three disk specimens from each mix were partially immersed in water and the weight gain was recorded at different intervals of time and up to 8 days. The reported results' standard deviation was within the allowable limit.

\subsubsection{Thermogravimetric Analysis (TGA)}

Thermogravimetric analysis was carried out on paste specimens at the ages of 28 and 360 days to study the weight loss (WL) at important phases. A SDT-Q600 model was used to get the readings.

\subsubsection{X-ray Diffraction (XRD) Analysis}

X-ray diffraction analysis was carried out on the paste specimens at the age of 28 days to study the mineralogy of the developed matrix. The main parameters input for the analysis in the Rikagu D8 machine included source of $\mathrm{Cu}-\mathrm{K}$, scanning velocity of $2.5 \mathrm{deg} / \mathrm{min}$, and voltage of $20 \mathrm{kV}$.

\subsubsection{Fourier Transform Infrared Spectroscopy (FT-IR) Analysis}

Fourier Transform Infrared Spectroscopy was performed on paste specimens after 28 days to study the molecular behavior and formation of functional groups using Thermo Fisher spectrometer.

\section{Results and Discussion}

\subsection{Flow}

Figure 2 shows the variation in mortar flow with addition of DPA dosages. The flow of mortar in all mixtures were within the plastic range (140 to $200 \mathrm{~mm}$ ), as per BS EN 1015 [15]. Maximum flow was measured in $100 \%$ OPC mortar, and flow tended to decrease with addition of DPA content. The mortar flow in $100 \%$ OPC was $180 \mathrm{~mm}$, which was about $5.5 \%, 12.7 \%$, and $16.1 \%$ higher than mortar prepared with $10 \%, 20 \%$, and $30 \%$ DPA, respectively. The drop in flow values with DPA addition was due to its coarser and irregular particles, in nature, than OPC, which resists mortar flow.

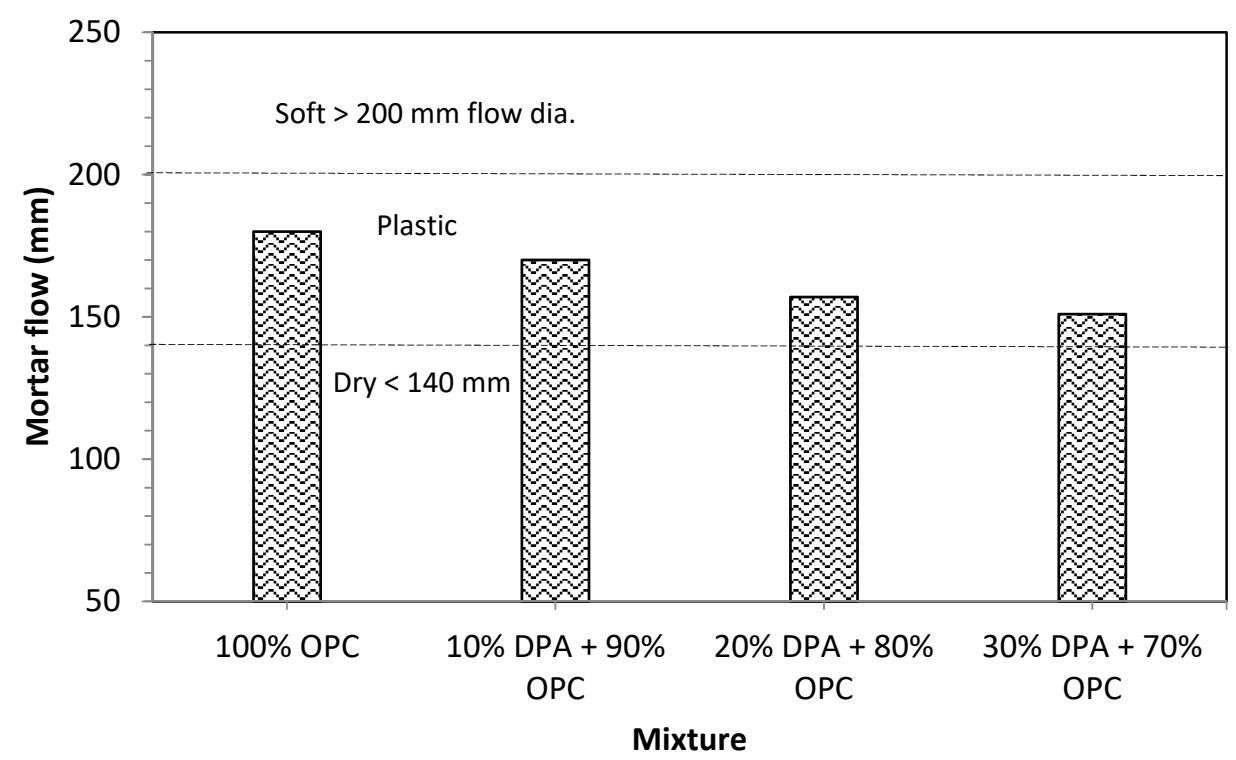

Figure 2. Mortar flow variation in all mixtures.

\subsection{Compressive Strength}

Figure 3 displays the compressive strength values in 100\% OPC, 10\% DPA, 20\% DPA, and 30\% DPA mortar specimens with curing period up to 360 days. The results showed that the optimum mix, yielding high compressive strength at all test ages, was 10\% DPA plus $90 \%$ OPC. At the early age of 3 days, the compressive strength of optimum mix was $43 \mathrm{MPa}$, which was $38 \%, 30 \%$, and $50 \%$ higher 
than those achieved by 100\% OPC, 20\% DPA, and 30\% DPA mixtures, respectively. The later and long-term age strength development was found to be comparable among 100\% OPC and 10\% DPA mixes, as well as among 20\% DPA and 30\% DPA mixtures. The 28-day compressive strength of $10 \%$ DPA specimens was about $57 \mathrm{MPa}$, which was 3\%, 24\%, and $29 \%$ higher than those attained by $100 \%$ OPC, $20 \%$ DPA, and 30\% DPA mixtures, respectively. Similarly, long-term strength of $10 \%$ DPA was $85.5 \mathrm{MPa}$, which was $4 \%, 27 \%$, and $28 \%$ more than the strength of $100 \%$ OPC, $20 \%$ DPA, and $30 \%$ DPA mixtures, respectively. The strength increment in the $10 \%$ DPA mix could be explained by the ability of DPA to produce higher secondary Calcium Silicate Hydrate (C-S-H), due to the presence of optimum lime content, as observed in TGA and XRD analysis.

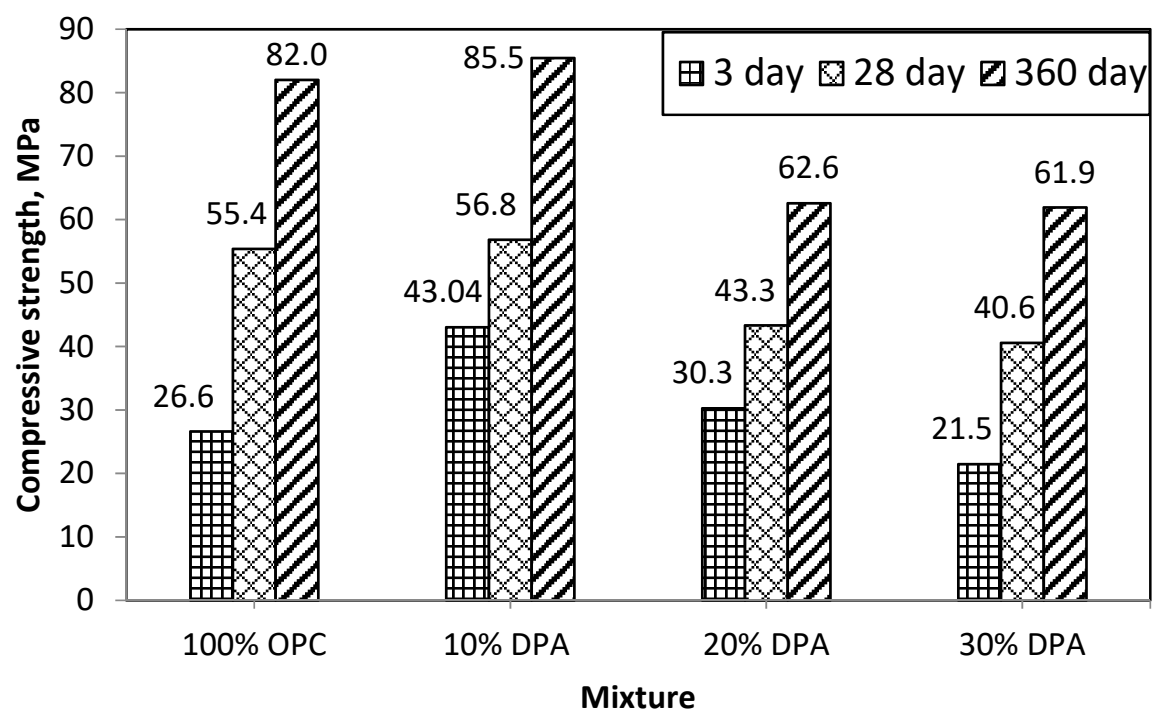

Figure 3. Compressive strength development in mortar mixtures.

\subsection{Rate of Water Absorption}

Figure 4 shows the rate of water absorption in $100 \%$ OPC, 10\% DPA, 20\% DPA, and 30\% DPA concrete specimens with respect to square root of time. An excellent correlation was noted both during initial (upto $6 \mathrm{~h}$ of immersion in water) and secondary (every $24 \mathrm{~h}$ upto 8 days) rate of water absorption, such that R-square value of approximately 0.9 was obtained. Figure 5 summarizes the maximum value of initial and secondary rate of water absorption in all concrete batches. It can be observed that $10 \%$ DPA-based concrete specimens resulted in minimum rate of water absorption, both at initial and final stages, followed by concrete containing 20\% DPA, 100\% OPC, and 30\% DPA, respectively. At 28 days, the maximum initial rate of water absorption was $0.54 \mathrm{~mm}$ in optimum (10\% DPA-based) concrete, which was about $35 \%, 27 \%$, and $41 \%$ lesser than $100 \%$ OPC, $20 \%$ DPA, and 30\% DPA samples, respectively. Likewise, the maximum secondary rate of water absorption was recorded as $1.92 \mathrm{~mm}$ in $10 \%$ DPA-based concrete, which was about $20 \%, 19.5 \%$, and $31 \%$ lower than $100 \%$ OPC, $20 \%$ DPA, and $30 \%$ DPA specimens, respectively. It was also noticed that percentage increment of maximum rate of water absorption among each concrete mixture, from its initial to secondary absorption, was smallest and highest, respectively, in 10\% and 20\% DPA-based concrete samples. The difference in maximum initial and secondary absorption values was about $66 \%, 72 \%, 69 \%$, and $67 \%$ in $100 \%$ OPC, $10 \%$ DPA, $20 \%$ DPA, and 30\% DPA-based concrete specimens, respectively. Similar pattern of water penetration was noted at 360 days, while reduction in absorption value is understandably due to higher binder maturity and strength with time. 


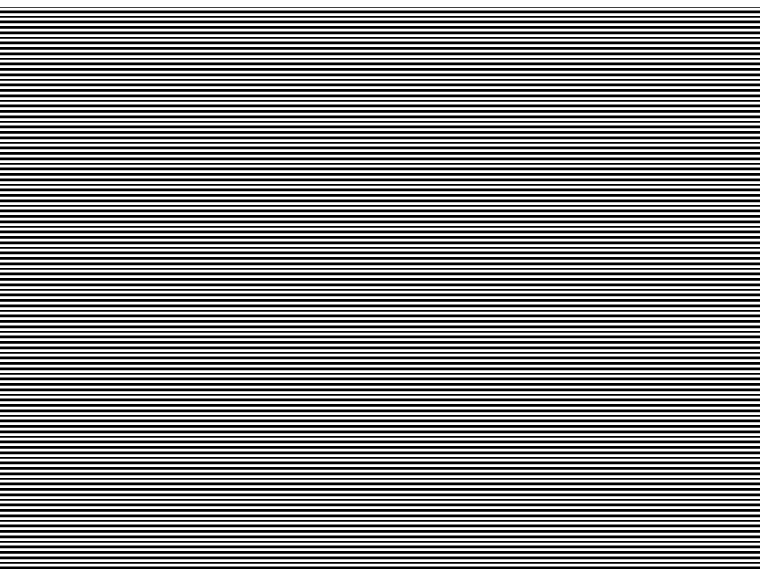

(a) $100 \%$ OPC.

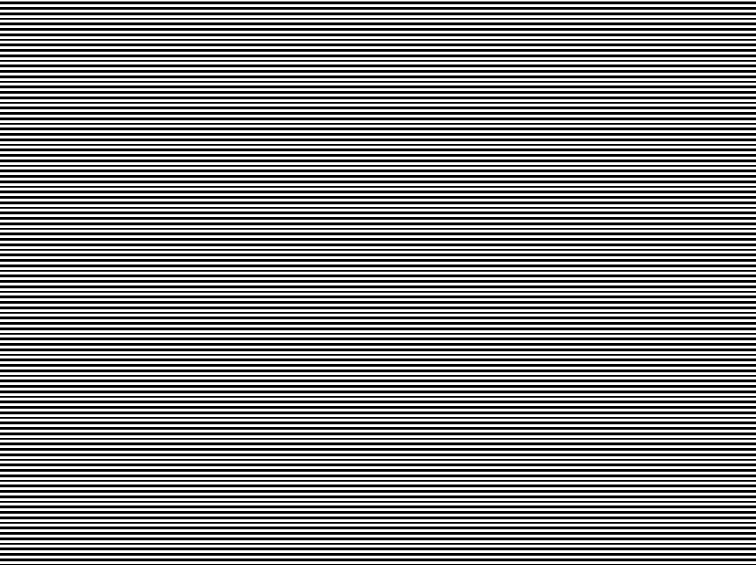

(c) $20 \%$ DPA.

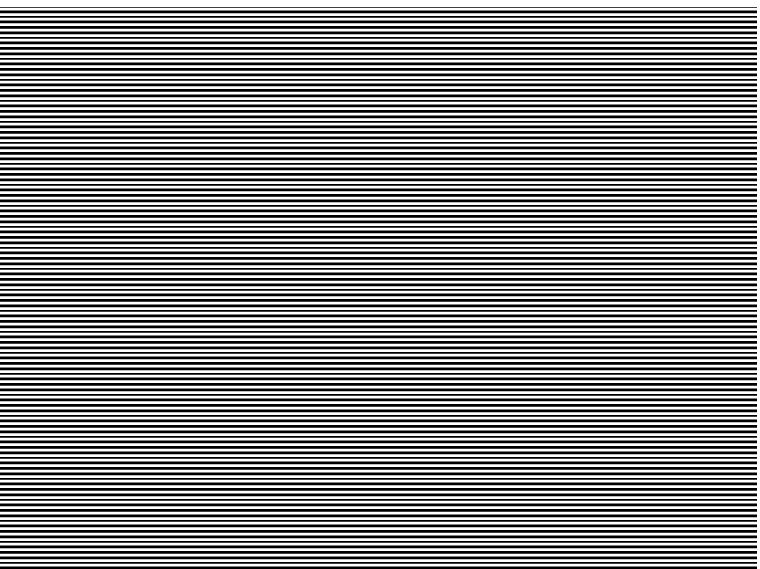

(b) $10 \%$ DPA.

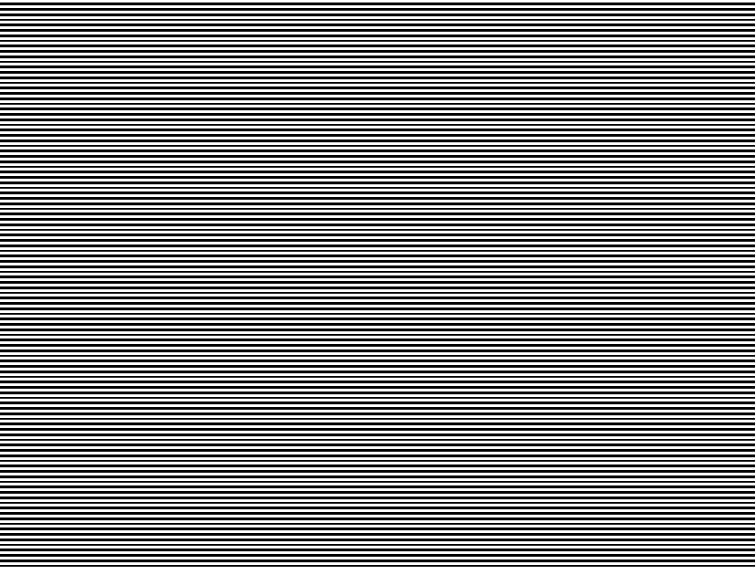

(d) $30 \%$ DPA.

Figure 4. Correlation between rate of water absorption and time at 28 days: (a) $100 \%$ OPC, (b) $10 \%$ DPA, (c) $20 \%$ DPA and (d) $30 \%$ DPA.

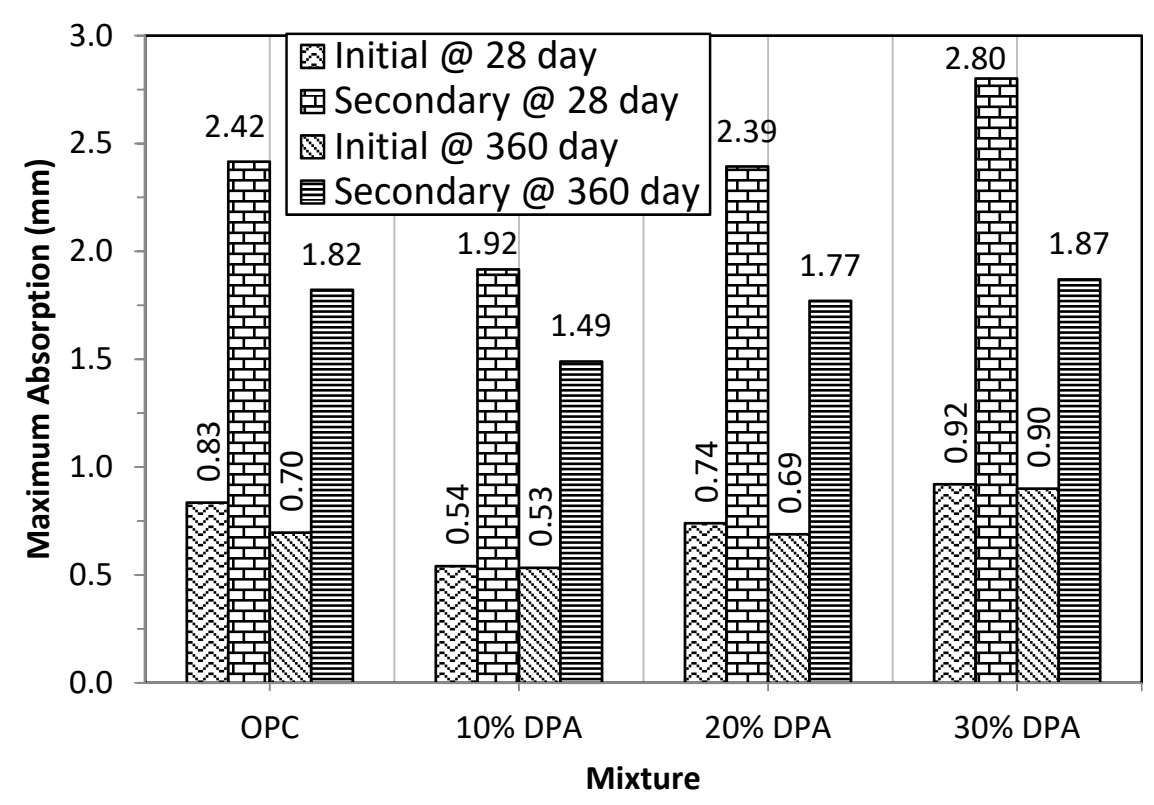

Figure 5. Maximum initial and secondary rate of water absorption in all concretes. 


\subsection{Thermogravimetric Analysis (TGA)}

Figures 6 and 7 show the weight loss (WL) with respect to temperature exposure at the age of 28 and 360 days. Tables 2 and 3 summarize the WL data, wherein hydrated gel phase and remnants of portlandite were calculated. Temperatures between 110 and $300{ }^{\circ} \mathrm{C}$ (Phase 1) indicate the decomposition of Calcium Silicate Hydrate (C-S-H) and Calcium Aluminosilicate Hydrate (C-A-S-H) gel, while sample exposure to temperature between 450 and $550^{\circ} \mathrm{C}$ (Phase 2) gives information of $\mathrm{CH}$ or $\mathrm{Ca}(\mathrm{OH})_{2}$ availability [16]. The 28-day TGA results demonstrate that WL increases with increase in DPA replacement, as compared to $100 \%$ OPC pastes. This shows that more hydrated gel products are present in DPA-based binary paste than OPC paste. About $5 \%, 7 \%$, and $23 \%$ more hydration products were formed in the mixes containing $30 \%, 20 \%$, and $10 \%$ DPA content, respectively. Moreover, $30 \%-45 \%$ lesser portlandite was available in the DPA-based paste matrix, as compared to the control mix, which is possibly consumed in the secondary hydration and pozzolanic reaction while reacting with silica, leading to additional hydrated gel and strength. After 360 days of curing, the control and $10 \%$ DPA mixes show approximately similar WL in phase 1; understandably OPC paste undergoes steady and long-term strength development. Additionally, 10\% DPA paste still constitute $13 \%$ extra portlandite, which can react with active silica in DPA and Al in OPC to form further gel products. The results further indicate that with more than $10 \%$ increment in DPA dosage there is no significant improvement in the hydration products. However, beside technical advantage, high DPA replacement could be encouraged for a sustainability and economy point of view. Both 28- and 360-day TGA results corroborate the strength results.

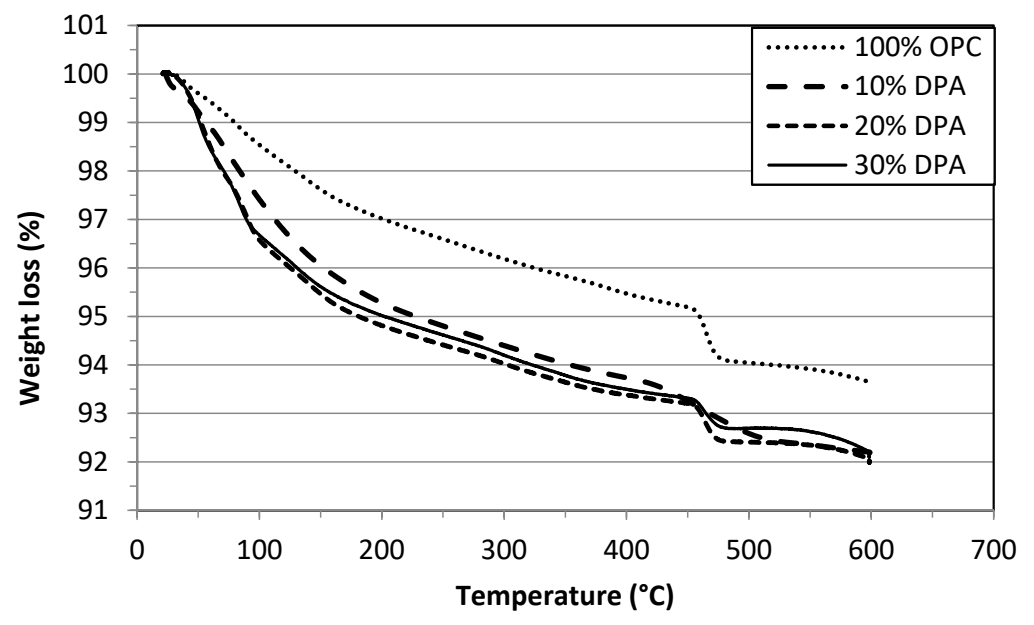

Figure 6. TGA curve at the age of 28 days.

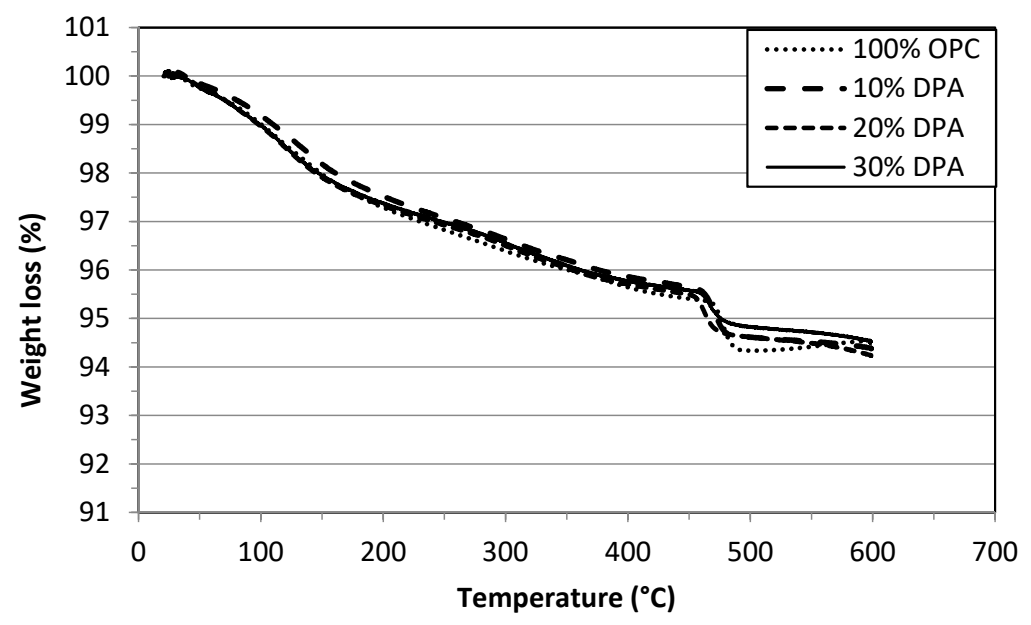

Figure 7. TGA curve at the age of 360 days. 
Table 2. Weight loss in paste mixtures at the age of 28 days.

\begin{tabular}{|c|c|c|c|c|c|}
\hline \multirow{3}{*}{ Paste Type } & \multirow{3}{*}{$\begin{array}{c}\text { Total WL } \\
\text { (\%) }\end{array}$} & \multirow{2}{*}{\multicolumn{2}{|c|}{$\begin{array}{c}\text { Phase 1: } 110-300\left({ }^{\circ} \mathrm{C}\right) \\
\text { Decomposition of } \\
\text { C-S-H + C-A-S-H }\end{array}$}} & \multirow{2}{*}{\multicolumn{2}{|c|}{$\begin{array}{c}\text { Phase 2: } 450-550\left({ }^{\circ} \mathrm{C}\right) \\
\text { Decomposition of } \\
\mathrm{Ca}(\mathrm{OH})_{2}\end{array}$}} \\
\hline & & & & & \\
\hline & & WL (\%) & $\mathrm{WL} / \mathrm{WL}$ in $\mathrm{OPC}$ & WL (\%) & WL/WL in OPC \\
\hline $100 \%$ OPC & 4.31 & 2.04 & 1.00 & 1.27 & 1.00 \\
\hline $10 \%$ DPA & 4.54 & 2.50 & 1.23 & 0.90 & 0.71 \\
\hline $20 \%$ DPA & 3.85 & 2.18 & 1.07 & 0.86 & 0.68 \\
\hline $30 \%$ DPA & 3.71 & 2.14 & 1.05 & 0.69 & 0.54 \\
\hline
\end{tabular}

Table 3. Weight loss in paste mixtures at the age of 360 days.

\begin{tabular}{|c|c|c|c|c|c|}
\hline \multirow{3}{*}{ Paste Type } & \multirow{3}{*}{$\begin{array}{c}\text { Total WL } \\
(\%)\end{array}$} & \multirow{2}{*}{\multicolumn{2}{|c|}{$\begin{array}{c}\text { Phase 1: } 110-300\left({ }^{\circ} \mathrm{C}\right) \\
\text { Decomposition of } \\
\text { C-S-H + C-A-S-H }\end{array}$}} & \multirow{2}{*}{\multicolumn{2}{|c|}{$\begin{array}{c}\text { Phase 2: } 450-550\left({ }^{\circ} \mathrm{C}\right) \\
\text { Decomposition of } \\
\mathrm{Ca}(\mathrm{OH})_{2}\end{array}$}} \\
\hline & & & & & \\
\hline & & WL (\%) & WL/WL in OPC & WL (\%) & $\mathrm{WL} / \mathrm{WL}$ in $\mathrm{OPC}$ \\
\hline $100 \%$ OPC & 4.24 & 2.27 & 1.00 & 0.99 & 1.00 \\
\hline $10 \%$ DPA & 4.14 & 2.24 & 0.99 & 1.12 & 1.13 \\
\hline $20 \%$ DPA & 4.16 & 2.15 & 0.95 & 0.99 & 1.00 \\
\hline $30 \%$ DPA & 3.98 & 2.13 & 0.94 & 0.87 & 0.88 \\
\hline
\end{tabular}

\subsection{Pore Volume Distribution in OPC and DPA Pastes}

Figures 8 and 9 show the pore size volume and surface area distribution with respect to pore radius, respectively, in control and DPA-based binary paste mixtures at the age of 28 days. Table 4 summarizes the pore size and surface area results. It can be observed that $100 \%$ OPC and $10 \%$ DPA pastes have similar total pore volume of about $0.046 \mathrm{~mL} / \mathrm{g}$. However, an increase in DPA content, up to $30 \%$, will lead to an increase in the total pore volume, up to $0.063 \mathrm{~mL} / \mathrm{g}$. This is most likely due to the high compatibility between OPC particles and DPA dosage, up to $10 \%$, that yields good packing effect, enabling high strength and low water permeability. Unexpectedly, the surface area of $100 \%$ OPC mix was minimum and it tended to increase with coarser DPA replacement level, which requires further investigation and correlation with other gas pycnometry and porosity techniques, like mercury intrusion porosimetry (MIP).

Table 4. Total pore volume, surface area, and average pore radius of paste mixtures at 28 days.

\begin{tabular}{cccc}
\hline Paste Type & Surface Area $\left(\mathbf{m}^{2} / \mathbf{g}\right)$ & Total Pore Volume $(\mathbf{m L} / \mathbf{g})$ & Average Pore Radius $(\mathbf{n m})$ \\
\hline $100 \%$ OPC & 7.900 & 0.046 & 23.221 \\
$10 \%$ DPA & 10.979 & 0.046 & 11.647 \\
$20 \%$ DPA & 11.461 & 0.053 & 11.647 \\
$30 \%$ DPA & 14.420 & 0.063 & 11.651 \\
\hline
\end{tabular}

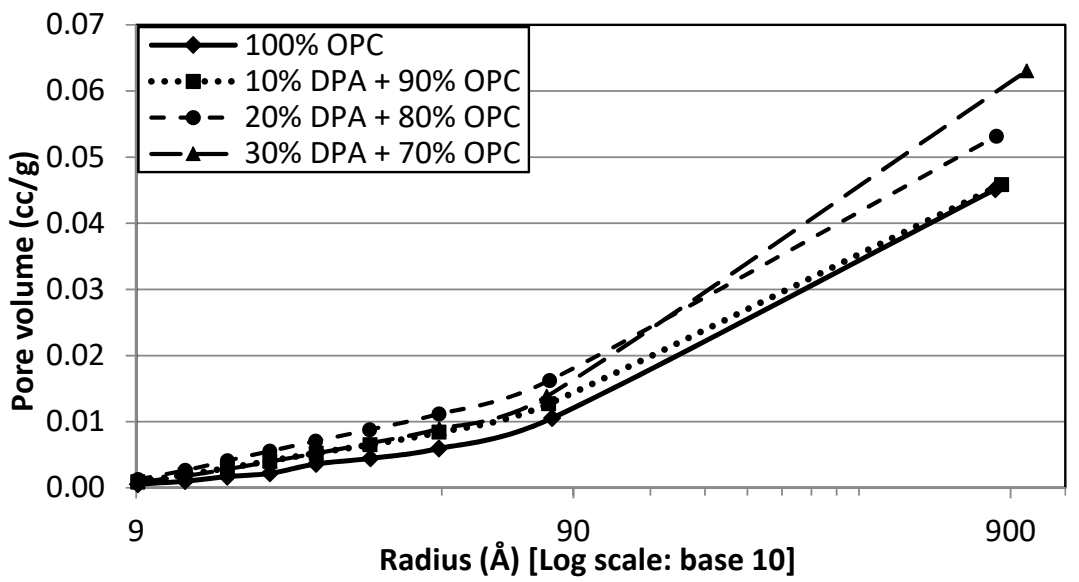

Figure 8. Pore volume distribution in all mixtures. 


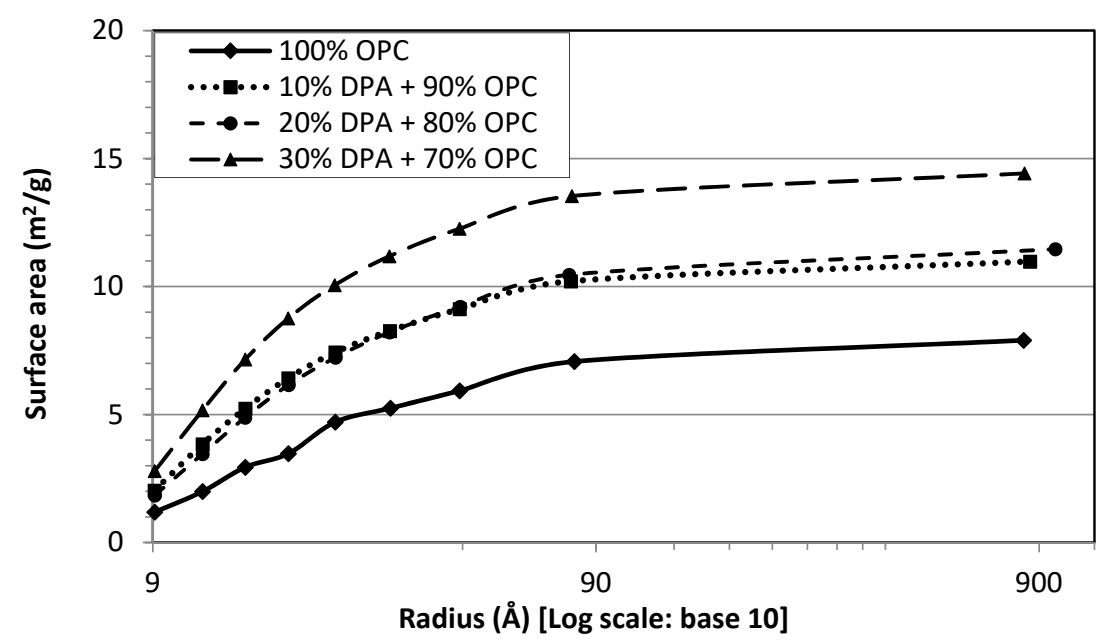

Figure 9. Surface area distribution in all mixtures.

\subsection{X-ray Diffraction (XRD) Analysis}

Figure 10 shows the X-ray diffractogram of 100\% OPC and DPA-based binary paste binders. High amorphous and semi-crystalline structure was observed between the range of 15 and 40 degree 2-theta. The identified peaks in XRD spectrum included: (1) portlandite, (2) stratlingite, (3) quartz, (4) garronite, (5) Calcium Silicate Hydrate (C-S-H), (6) wollastonite, (7) hydrotalcite, and (8) Calcium Aluminosilicate Hydrate (C-A-S-H). As silica content in XRF results (Table 1) increases with increase in DPA dosages, the quartz peaks in the binder becomes shorter, imparting the amorphousness. On contrary, the lime content is decreasing with increase in DPA content, leading to weak C-S-H, C-A-S-H gel, and phases like wollastonite and stratlingite in the hydrated matrices of binary binder, having more than $10 \%$ DPA. Thus, the role of calcium is more vital than silica in the formation of gel crystals and in the strength development of $100 \%$ OPC and 10\% DPA-based mortar. Such finding was also reported in natural pozzolan, fly ash, and slag-based binders [17-19]. Other notable phases contributing to minor strength were identified as garronite and hydrotalcite, due to the presence of $\mathrm{Mg}$ and $\mathrm{Al}$.

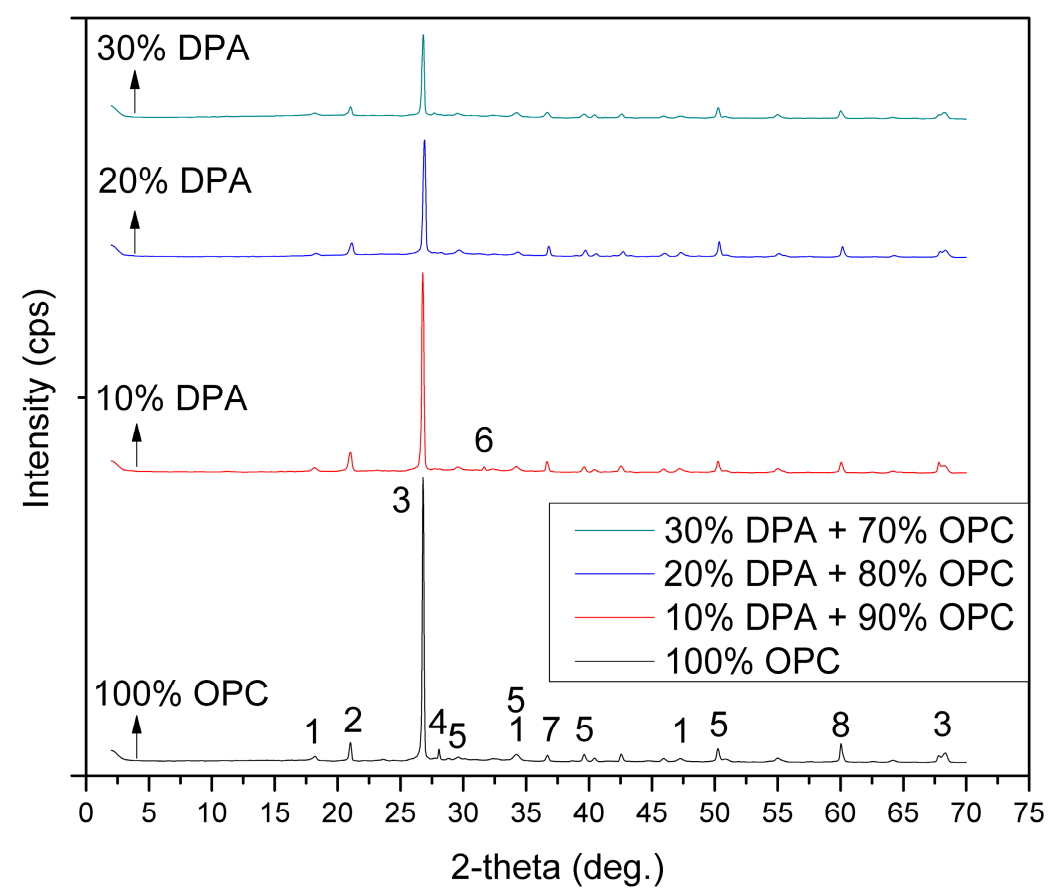

Figure 10. XRD spectra of binders at 28 days. Phases at peak IDs: 1 -portlandite, 2 -stratlingite, 3-quartz, 4-garronite, 5-C-S-H, 6-wollastonite, 7-hydrotalcite, and 8-C-A-S-H. 


\subsection{Fourier Transform Infrared Spectroscopy (FT-IR) Analysis}

Figure 11 displays the FT-IR spectrum of as received DPA and hydrated paste binders. As expected, significant change in molecular behavior occurred in paste samples, as compared to pure DPA after the hydraulic and pozzolanic reaction. Peaks between wavelength number $500-600 \mathrm{~cm}^{-1}$ represents vibrating molecules of $\mathrm{Si}-\mathrm{O}$, and its capable of transforming the reactivity from raw DPA to the paste binders. Symmetric vibrating band at $690 \mathrm{~cm}^{-1}$ in pure DPA is due to Si-O-Al and Si-O-Si covalent bonds, which enables the formation of C-A-S-H gel in the paste binders [20]. Bending peak at $875 \mathrm{~cm}^{-1}$ corresponds to the carbonation band [21], which was shifted to lower bands in the form of double wavy peaks at 775-795 cm-1. Presence of asymmetric band at $1430 \mathrm{~cm}^{-1}$ confirms the carbonation group in raw DPA [22]. This indicates that development of OPC-based binder significantly resists possibility of carbonation from the pure DPA. Symmetric band with medium intensity at $900-1100 \mathrm{~cm}^{-1}$ is a characteristic band that usually exists in Portland cement-based binder, and depends on the ratio of $\mathrm{Si}$ and $\mathrm{Al}$ in the form of $\mathrm{Si}-\mathrm{O}-\mathrm{T}(\mathrm{T}=\mathrm{Si} / \mathrm{Al})$ [23]. Stretching peaks at 1740 and $3385 \mathrm{~cm}^{-1}$ depict $\mathrm{H}-\mathrm{O}-\mathrm{H}$ bonds, due to interlayer water in the paste. These bands were not detected in the $100 \%$ OPC and $10 \%$ DPA-based binder, indicating that the mix water was completely utilized in the hydraulic and pozzolanic reaction, enabling these binders to achieve higher strengths. Such finding is in compliance with a study based on geopolymer binder [24].

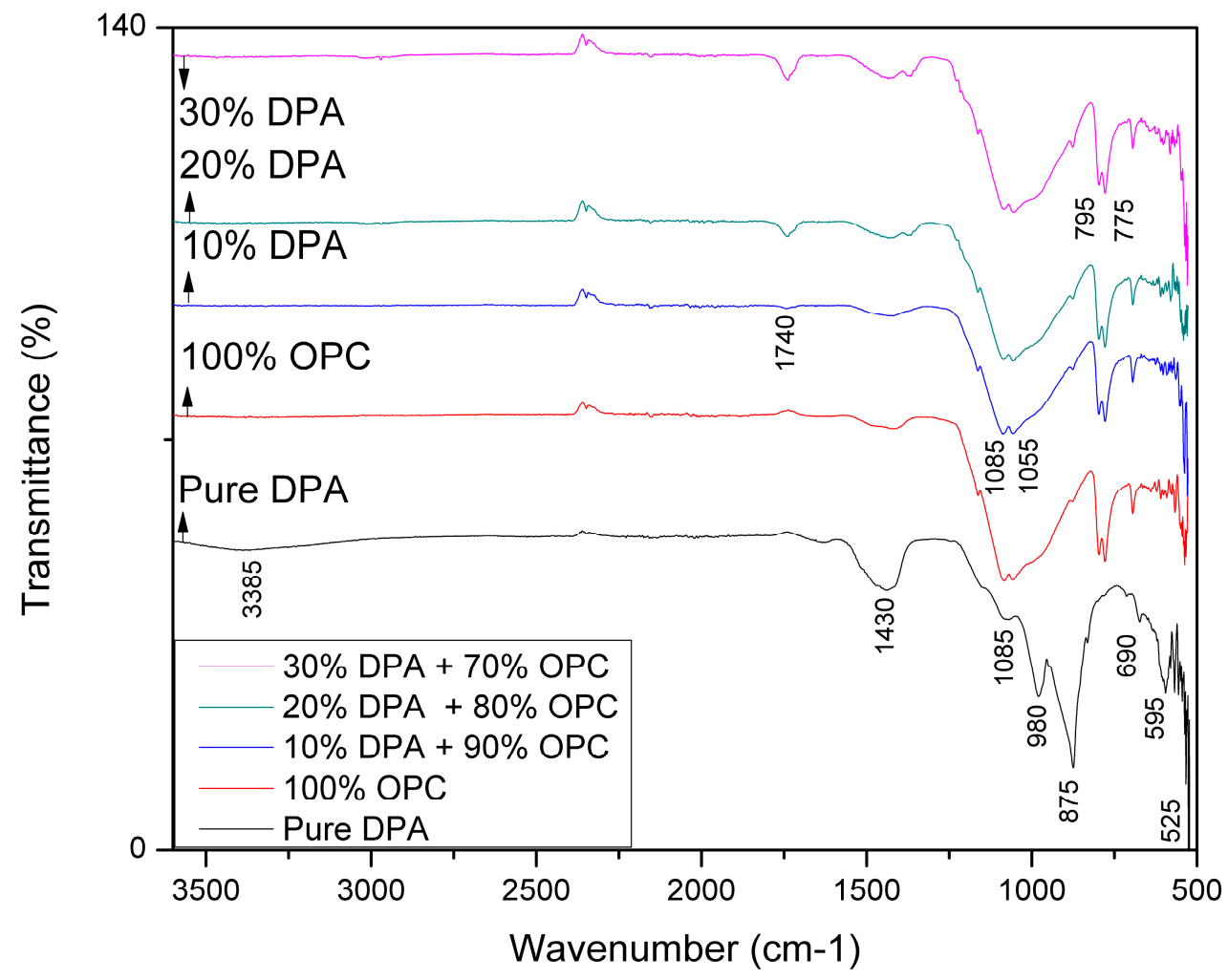

Figure 11. FT-IR spectra of pure DPA and binders at 28 days.

\section{Conclusions}

The primary objective of this study was to investigate the effect of date palm ash (DPA) replacement levels into ordinary Portland cement (OPC). Representative fresh, mechanical and durability properties were carried out to establish the optimum DPA dosage. Analytical tests were conducted to study the reaction mechanism of DPA in the binary system. All test properties revealed that the 10\% DPA and $90 \%$ OPC-based binder was optimum. However, up to $30 \%$ OPC could be beneficially replaced with DPA for reasonable strength and durability, as well as to cut the construction 
cost and enhance sustainability. Based on the experimental outcomes, the following conclusions can be drawn:

1. Flow decreased with increase in DPA dosage due to its coarser nature, as compared to OPC, while the flow was found to be within plastic range, up to $30 \%$ DPA content.

2. Compressive strength of mortar increased with DPA dosage, up to $10 \%$, and thereafter was negatively affected. Strength of mortar prepared with $10 \%$ DPA replacement was 43,57 , and $85.5 \mathrm{MPa}$, respectively, at 3, 28, and 360 days. Long-term (28 days onwards) strength in the $100 \%$ OPC and the $10 \%$ DPA-based mixes were comparable.

3. Rate of water absorption in concrete specimens followed the same trend as evident in the compression test. Greater resistance, of $20 \%-30 \%$, to water penetration was noted in the optimum mix compared to other mixes, indicating good durability against ingress of aggressive species in concrete.

4. TGA results showed $23 \%$ higher formation of C-S-H and C-A-S-H gel, as well as lower CH, leading to higher strength and durability by means of sufficient hydration and pozzolanic reaction in the optimum paste mix. The results of 360 days also showed the same trend with lower weight losses.

5. Cumulative pore volume in optimum mix was comparable to the control mix, which accounts for $0.046 \mathrm{~mL} / \mathrm{g}$. Pore distribution showed direct relationship with DPA dosage.

6. XRD analysis revealed the presence of strong C-S-H and C-A-S-H gel in the optimum mix, together with the existence of wollastonite and stratlingite phases in the hydrated matrices, which contributed to the strength development.

7. FT-IR spectrum confirmed the formation of C-A-S-H gel and covalent bonds between $\mathrm{Si}$ and $\mathrm{Al}$ in the paste mixtures. Absence of water bands in the optimum and control mixtures indicated the possibility of more hydraulic and pozzolanic reaction in them, which yielded high strength and durability.

It is recommended to extend this work by evaluating the durability performance of DPA-based concrete in the sulfate and acid environment, as well as to monitor chloride diffusion and reinforcement corrosion.

Author Contributions: Both authors contributed in the development of binders, testing program, analysis of results and preparation of the manuscript.

Funding: This research received no external funding.

Acknowledgments: The authors are grateful to the Deanship of Scientific Research (DSR) at Imam Abdulrahman Bin Faisal University for their support under the research grant No. 2017-314-Eng.

Conflicts of Interest: The authors declare no conflict of interest.

\section{References}

1. CSI Council. Global Cement Database-Cement Sustainability Initiative. 2015. Available online: http: //www.wbcsdcement.org/ (accessed on 1 February 2018).

2. Worrell, E.; Price, L.; Martin, N.; Hendriks, C.; Meida, L.O. Carbon dioxide emissions from the global cement industry. Annu. Rev. Energy Environ. 2001, 26, 303-329. [CrossRef]

3. Meinshausen, M.; Meinshausen, N.; Hare, W.; Raper, S.C.; Frieler, K.; Knutti, R.; Frame, D.J.; Allen, M.R. Greenhouse-gas emission targets for limiting global warming to 2 C. Nature 2009, 458, 1158-1162. [CrossRef]

4. Portland Cement Association. Flash Report-The Monitor; Portland Cement Association: Skokie, IL, USA, 2004.

5. Estrellan, C.R.; Iino, F. Toxic emissions from open burning. Chemosphere 2010, 80, 193-207. [CrossRef]

6. Aprianti, E.; Shafigh, P.; Bahri, S.; Farahani, J.N. Supplementary cementitious materials origin from agricultural wastes-A review. Constr. Build. Mater. 2015, 74, 176-187. [CrossRef]

7. Agoudjil, B.; Benchabane, A.; Boudenne, A.; Ibos, L.; Fois, M. Renewable materials to reduce building heat loss: Characterization of date palm wood. Energy Build. 2011, 43, 491-497. [CrossRef] 
8. Haimour, N.M.; Emeish, S. Utilization of date stones for production of activated carbon using phosphoric acid. Waste Manag. 2006, 26, 651-660. [CrossRef] [PubMed]

9. Abdelouahhab, Z.; Arias-Jimenez, E.J. Date Palm Cultivation; Food and Agriculture Organization (FAO): Rome, Italy, 1999; No. 156.

10. Assirey, E.A.R. Nutritional composition of fruit of 10 date palm (Phoenix dactylifera L.) cultivars grown in Saudi Arabia. J. Taibah Univ. Sci. 2015, 9, 75-79. [CrossRef]

11. Khellou, A.; Kriker, A.; Hafssi, A.; Belbarka, K.; Baali, K. Effect of the addition of by-product ash of date palms on the mechanical characteristics of gypsum-calcareous materials used in road construction. AIP Conf. Proc. 2016, 1758, 030005.

12. Al-Kutti, W.; Islam, A.B.M.S.; Nasir, M. Potential use of date palm ash in cement-based materials. J. King Saud Univ. Sci. 2017. [CrossRef]

13. Al-Kutti, W.; Nasir, M.; Johari, M.A.M.; Islam, A.B.M.S.; Manda, A.A.; Blaisi, N.I. An overview and experimental study on hybrid binders containing date palm ash, fly ash, OPC and activator composites. Constr. Build. Mater. 2018, 159, 567-577. [CrossRef]

14. Gunarani, G.I.; Chakkravarthy, S.P. Experimental studies on effect of Date Seed Ash (DSA) on strength properties of cement sand mortar. IOP Conf. Ser. Earth Environ. Sci. 2017, 80, 012015. [CrossRef]

15. BS EN 1015. Determination of Consistence of Fresh Mortar by Flow Table and Bulk Density; BSI: London, UK, 1999.

16. Collier, N.C. Transition and decomposition temperatures of cement phases-A collection of thermal analysis data. Ceram.-Silik. 2016, 60, 338-343. [CrossRef]

17. Ismail, I.; Bernal, S.A.; Provis, J.L.; San Nicolas, R.; Hamdan, S.; van Deventer, J.S.J. Modification of phase evolution in alkali-activated blast furnace slag by the incorporation of fly ash. Cem. Concr. Compos. 2014, 45, 125-135. [CrossRef]

18. Palomo, A.; Fernández-Jiménez, A.; Kovalchuk, G.; Ordoñez, L.M.; Naranjo, M.C. Opc-fly ash cementitious systems: Study of gel binders produced during alkaline hydration. J. Mater. Sci. 2007, 42, 2958-2966. [CrossRef]

19. Moon, J.; Bae, S.; Celik, K.; Yoon, S.; Kim, K.H.; Kim, K.S.; Monteiro, P.J. Characterization of natural pozzolan-based geopolymeric binders. Cem. Concr. Compos. 2014, 53, 97-104. [CrossRef]

20. Renaudin, G.; Russias, J.; Leroux, F.; Cau-dit-Coumes, C.; Frizon, F. Structural characterization of C-S-H and C-A-S-H samples-Part II: Local environment investigated by spectroscopic analyses. J. Solid State Chem. 2009, 182, 3320-3329. [CrossRef]

21. Lecomte, I.; Henrist, C.; Liegeois, M.; Maseri, F.; Rulmont, A.; Cloots, R. (Micro)-structural comparison between geopolymers, alkali-activated slag cement and Portland cement. J. Eur. Ceram. Soc. 2006, 26, 3789-3797. [CrossRef]

22. Huang, C.K.; Kerr, P.F. Infrared study of the carbonate minerals. Am. Miner. 1960, 45, 311-324.

23. Ravikumar, D.; Neithalath, N. Effects of activator characteristics on the reaction product formation in slag binders activated using alkali silicate powder and $\mathrm{NaOH}$. Cem. Concr. Compos. 2012, 34, 809-818. [CrossRef]

24. Yusuf, M.O.; Johari, M.A.M.; Ahmad, Z.A.; Maslehuddin, M. Strength and microstructure of alkali-activated binary blended binder containing palm oil fuel ash and ground blast-furnace slag. Constr. Build. Mater. 2014, 52, 504-510. [CrossRef]

(C) 2018 by the authors. Licensee MDPI, Basel, Switzerland. This article is an open access article distributed under the terms and conditions of the Creative Commons Attribution (CC BY) license (http://creativecommons.org/licenses/by/4.0/). 